\title{
The Toxic Effects of Low Molecular Weight Components of Cow Colostrums: The Short-Term and Long-Term Effects
}

\author{
A.I. Bozhkov*, E.G. Ivanov, N.I. Kurguzova, Muhammad M.A. Alsardia, R.A. Akzhigitov, \\ S.Ya. Baranikova, V.I. Potapova and A.S. Chuprikova
} Research Institute of Biology V.N. Karazin Kharkiv National University, 4, Svobody Sq., 61022 Kharkov,
Ukraine

\begin{abstract}
Background: Low-molecular components of colostrum (LMWCC) have a pronounced biological activity. We investigated the effect of different doses of $\operatorname{LMWCC}(0.01,0.1,1$ and $5 \mathrm{~g} / 100 \mathrm{~g}$ of body weight) on the behavior, dynamics of growth, acute and chronic toxicity, as well as the relative weight of the liver, spleen and kidneys of the experimental animals.
\end{abstract}

Methods: We used 100 3-month male rats in the experiment. All animals were divided into 5 groups of 20 animals in each group, LMWCC was administered per os, and the control group received sterile water.

Results: LMWCC revealed no pirogenic effect in a wide diapason of doses $(0,01-5 \mathrm{~g} / 100 \mathrm{~g}$ of animal mass). Immediately after the LMWCC administration the short-time decrease in the motion activity was observed. The low doses of LMWCC induced diarrhea in $10-20 \%$ of of animals, the super-large dose - in $75 \%$ of animals. The acute toxicity of LMWCC (death of $15 \%$ of animals) was detected only in super-large dose of LMWCC and it was accompanied by pronounced diarrhea. LMWCC influenced the mass of liver, spleen and kidney. 60 days after LMWCC administration the mass of liver was restored to control weight, but the mass of spleen and kidney was not restored.

Conclusion: LMWCCdo not have chronic toxicity and can be attributed to non-toxic compounds with a possible side effect - a violation of the digestive system.

Keywords: Toxicity, Colostrum, Diarrhea.

\section{INTRODUCTION}

Colostrum is a unique biologically active product that is formed in the mammary gland of mammals in the first few days (up to 5 days) after the beginning of lactation [1, 2].

It can be assumed that reproduction of colostrum is an important evolutionary "acquisition", what promotes the resistance of newly born mammals to aggressive action of environmental factors. Moreover, at early stages of the postnatal development, the epigenetic memory and metabolic memory are formed and remained throughout the ontogenesis, and the colostrum components may influence their formation $[3,4]$.

It is known that a large number of biologically active compounds enter into the composition of colostrum that affects the functions of the immune system [5, 6]; it removes inflammatory reactions [7-9]; it is used even in the treatment of a number of serious pathologies [1012].

At the present time, a transfer factor has been isolated from the colostrum, which shows an expressed

\footnotetext{
*Address correspondence to this author at the Research Institute of Biology V.N. Karazin National University of Kharkov, 4, Svobody Sq., 61022 Kharkov, Ukraine; E-mail: bozhkov@univer.kharkov.ua
}

biological activity [13, 14]. However, its isolation and purification is a labor-intensive task and high-priced.

Along with this, we have isolated a complex of relatively low-molecular components of the colostrum, which eliminates the manifestations of the liver fibrosis [15] and has an immunomodulatory and antioxidant effect $[16,17]$.

Taking into consideration the high biological value, colostrum components can be used in the development of functional food products [18]. At the same time, the researchers face a number of complex problems when using colostrum as a raw material o receive biologically active compounds: the composition of colostrum changes hour after hour after the calving [19, 20]; the received colostrum is not stored, and it continues to change due to the multicomponent composition; it is technologically difficult to process, as it has a lot of fat and protein and even whole cells.

Most of the existing technologies for the colostrum processing are based on the isolation of separate colostrum components with their subsequent modification [15-17].

We previously isolated the relatively low-molecular components of the colostrum (LMWCC) and determined their biological activity [21, 22]. 
One of the main and defining stages in the research of functional food products is the determination of the effect of different doses on a number of vital physiological indexes. Along with this, the problem of dose dependence has become more acute in recent years not only in relation to xenobiotics but also to food products, in connection with the described effects of the action of small and ultra-small doses [23, 25].

In this regard, the effect of large doses of LMWCC is of the utmost interest. There is a belief that traditional products of biological origin should not be toxic and their research is not given due attention as a rule. Moreover, the research of the dose dependence of the physiological effects of LMWCC is important not only for the establishment of therapeutic and preventive doses, but also in the research of the mechanisms of their action.

In this work we investigated the effect of different doses of LMWCC: from small $(0.01 \mathrm{~g} / 100 \mathrm{~g}$ of body weight), potentially therapeutic $(0.1 \mathrm{~g} / 100 \mathrm{~g}$ of body weight), large (1 g/100 $\mathrm{g}$ of body weight) and "superlarge" ( $5 \mathrm{~g} / 100 \mathrm{~g}$ of body weight), on the behavior and general condition (presence of diarrhea, body weight and body temperature), as well as the manifestation of toxicity in experimental animals).

\section{MATERIALS AND METHODS}

\section{Experimental Models}

The experiments were conducted on 3-month mature males of the Wistar line. Animals were kept in standard vivarium conditions - they always received food and water at the same time of a day (9-11 a.m.) ad libitum. All manipulations (administration of LMWCC, weighing, temperature measurements) were always conducted at the same time of a day from 9:00 to $11: 00$ local time.

LMWCC was obtained from colostrum only of the first milk yield after the parturation, as it was described earlier [15]. In this purpose all lipid components were eliminated by three consequent separations. The proteins were eliminated by centrifugation at $6000 \mathrm{~g}$ during $10 \mathrm{~min}$ at room temperature and consequent membrane gel-filtration $(0,65 \rightarrow 0,45 \rightarrow 0,22 \mu \mathrm{m})$. The protein contents of colostrums was assessed by electrophoresis in polyacrilamide gel. LMWCC included proteins of molecular mass less than 25-30 kD [15]. A suspension of freeze-dried LMWCC was dissolved on sterile distilled water before the administration and it was administered per os at the same time of the day from 9:00 to 11:00 local time. The control group of animals was administered the sterile distilled water per os. The experiments were conducted on 100 intact animals, i.e. there were 20 animals in each experimental group that received different doses of LMWCC $-0.01 ; 0.1 ; 1$ and $5 \mathrm{~g} / 100 \mathrm{~g}$ of body weight.

\section{Methods for Determining the Physiological Indexes}

The motion activity was determined on the basis of expert assessments according to a points system where the usual physiological activity of animals was taken for 5 points, and inactivity - 1 point. The assessment of motion activity was carried out by three independent experts and the obtained data were averaged.

The presence of diarrhea was determined visually, and rectal body temperature was measured with a special thermometer for laboratory animals (USA), body weight and organ weight were determined by weight method.

The weight of the liver, spleen and kidneys was determined at 30 and 60 days after the first administration of LMWCC, while animals were immersed in ether anesthesia and all manipulations with animals were carried out in compliance with the accepted bioethical rules [25].

The obtained results were processed statistically using the "Excel" program and the differences between the control and experimental groups were considered reliable at $p \leq 0.05$.

\section{RESULTS}

The Influence of Different Doses of LMWCC on some Physiological Indexes of the Control Group of Animals after a Single Administration per os

The administration of even a small dose of LMWCC, $0.01 \mathrm{~g} / 100 \mathrm{~g}$ of body, induced diarrhea in $10-20 \%$ of the experimental animals and was accompanied by a loss of motion activity at 1-5 hours after the administration, and the motion activity was restored and did not differ from the control group at 10 hours after the administration (Figure 1A). A 10-fold increase of LMWCC dose was accompanied by the same suppression of animal activity as at a dose of 0.01 $\mathrm{g} / 100 \mathrm{~g}$ of body, the only difference being that they were restored more slowly (Figure $\mathbf{1 A}$ ). 

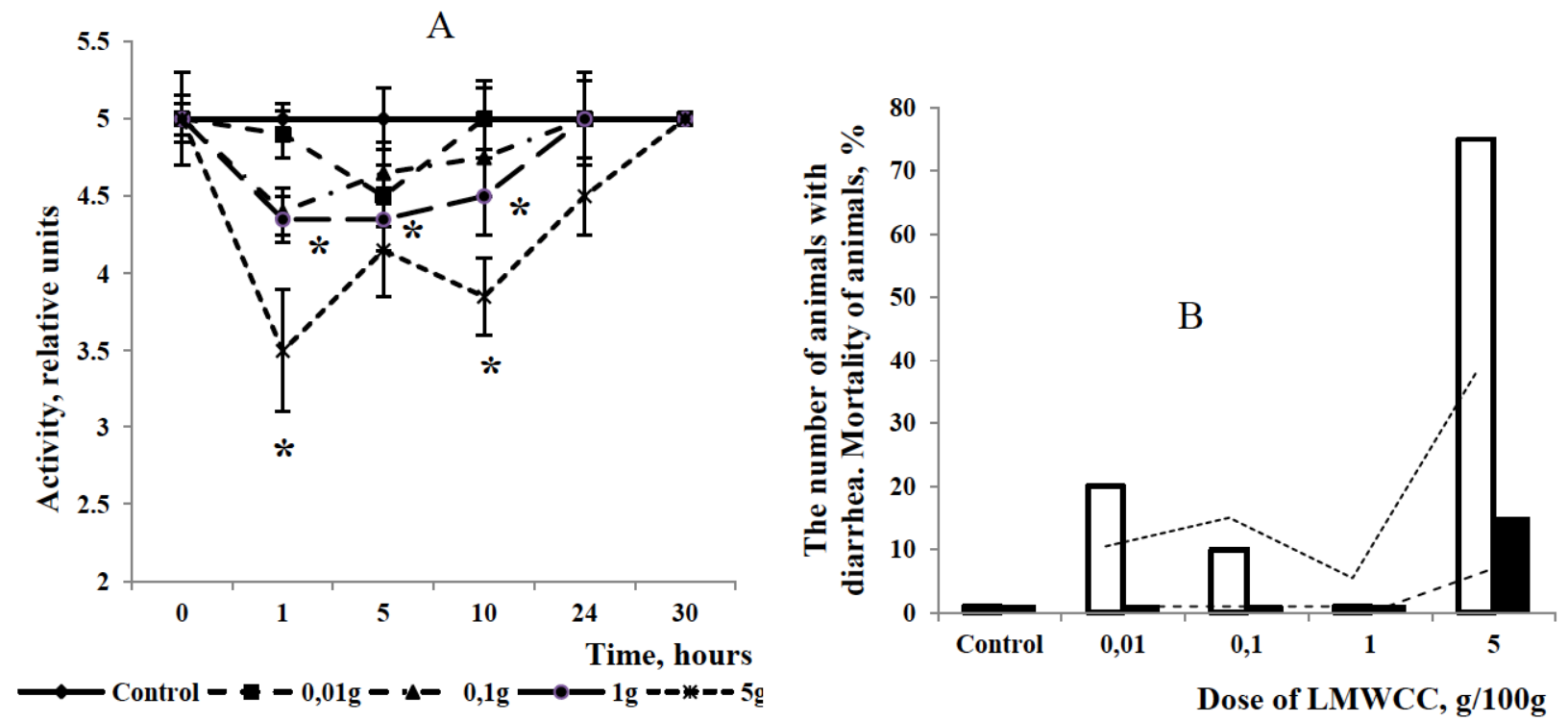

Figure 1: The motion activity of the experimental animals of the control group, and the animals that were administered LMWCC per os on a single occasion at doses: $0.01 \mathrm{~g} / 100 \mathrm{~g} ; 0.1 \mathrm{~g} / 100 \mathrm{~g} ; 1 \mathrm{~g} / 100 \mathrm{~g}$ and $5 \mathrm{~g} / 100 \mathrm{~g}$ at 1,5 and 10 hours after the administration (A). The number of animals in percentage who had diarrhea ( $\square$ ) and it was registered death ( $\mathbf{\square})$ at 10 hours after the administration of different doses of LMWCC $(B) .{ }^{*}-p<0,05$ in comparison with the control.

A 10 -fold increase in the dose, that is up to $1 \mathrm{~g} / 100$ $\mathrm{g}$ of body weight, suppressed the motion activity to a greater extent (Figure 1A), which was restored only at 24 hours after a single administration.

It should be noted that the dose of $1 \mathrm{~g}$ per $100 \mathrm{~g}$ of body, if it is converted to an adult human with an average weight of $70 \mathrm{~kg}$, would be 700 grams of colostrum in a single dose, which is an excessively large dose for the drug or food additive. If the dose of LMWCC was increased to $5 \mathrm{~g}$ per $100 \mathrm{~g}$ of body weight, which would be $3.5 \mathrm{~kg}$ for an adult human (that is a "super-large" dose), it strongly suppressed the activity of animals that did not restore even at 24 hours after the administration (Figure 1B).

Consequently, a single administration of LMWCC to experimental animals in a wide range of doses - from 0.01 to $5 \mathrm{~g}$ per $100 \mathrm{~g}$ of body weight, was accompanied by dose- and time-dependent suppression of motion activity, which was especially expressedat a dose of 5 $\mathrm{g}$ per $100 \mathrm{~g}$ of body weight.

The loss of motion activity after the administration of LMWCC in large doses could be due to their effect on the function of the digestive and other systems of the body. Indeed, at 10 hours after the administration of even a small dose $(0.01 \mathrm{~g}$ per $100 \mathrm{~g}), 20 \%$ of the animals showed mild diarrhea, and it was absentat 24 hours, i.e. they completely recovered. However, an increase of LMWCC dose up to $0.1 / 100 \mathrm{~g}$ caused diarrhea only in $10 \%$ of animals, and at a dose of 1 $\mathrm{g} / 100$ it was not detected (Figure 1B), i.e. there was a linear decrease of the effect in this range. After the administration of a "super-large" dose of LMWCC (5 $\mathrm{g} / 100 \mathrm{~g}$ ), diarrhea was detected in $75 \%$ of the animals and they recovered slowly (Figure 1B).

Moreover, if diarrhea passed quickly at doses of LMWCC $0.01-1 \mathrm{~g}$ per $100 \mathrm{~g}$ of body weight, and it was absent in all animalsat 24 hours after the administration of LMWCC, it was accompanied by $15 \%$ of the animal death in the group that received $5 \mathrm{~g}$ per $100 \mathrm{~g}$ of body weight (Figure 1B). Animal death was not observed in other groups (Figure 1B).

Consequently, the components of LMWCC do not have a toxic effect and they influence on the function of the digestive system at large doses, as a result, the motion activity is suppressed in healthy animals and a part of the animals died at a very large dose ( $5 \mathrm{~g}$ per $100 \mathrm{~g}$ of body weight), i.e. super-large doses can show the toxicity, which is associated with a violation of the function of digestion and intoxication, and, as a result, cause the death of animals.

\section{The Influence of Different Doses of LMWCC on some Physiological Indexesin Animals in a Chronic Experiment}

As it is known, the change of body weight is an integral index of metabolic activity and it correlates well with the changes in body weight at chronic pathologies. The increase of body weight is not a constant and 

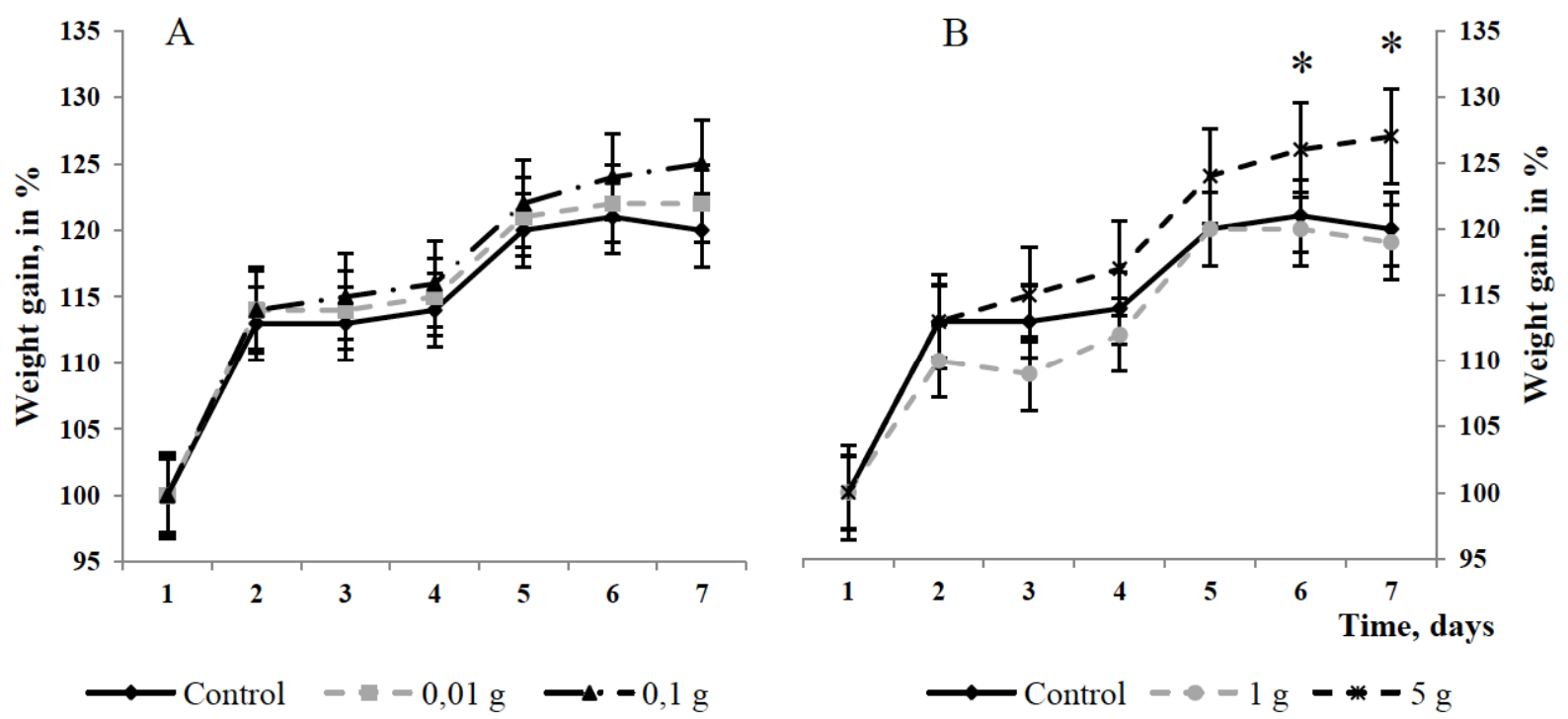

Figure 2: Weight gain as the percentage of initial which is taken as $100 \%$. For the experimental groups: control, received distilled water at a dose of $0.5 \mathrm{ml}$ for 7 days; animals received LMWCC at a dose of $0.01 \mathrm{~g}$ per $100 \mathrm{~g}$ daily for 7 days; animals received LMWCC at a dose of $0.1 \mathrm{~g}$ per $100 \mathrm{~g}$ daily for 7 days $(\mathbf{A})$; and control, received distilled water at a dose of $0.5 \mathrm{ml}$ for 7 days; animals received LMWCC at a dose of $1 \mathrm{~g}$ per $100 \mathrm{~g}$ on a single occasion, animals received LMWCC at a dose of $5 \mathrm{~g}$ per $100 \mathrm{~g}$ on a single occasion (B)

depends on feeding conditions, seasonality, physical activity and number of other factors [26, 27].

The control group of the 3-month animals, which were also influenced (weighing, administration of water per os, temperature measurement) was characterized by nonlinear growth (Figure 2A). The non-linearity of body weight growth can be explained by the manifestation of stress reactions caused by the manipulations with animals.

The daily administrations of LMWCC at a small dose of $0.01 \mathrm{~g} / 100 \mathrm{~g}$ of body weight did not influence on the change of body weight for 7 days (Figure 2). An increase of the dose of LMWCC up to $0.1 \mathrm{~g} / 100 \mathrm{~g}$ of body weight was accompanied by a slight stimulation of the animals' growth, which manifested itself on the $5^{\text {th }}$ $7^{\text {th }}$ day (Figure 2 ).

Since the repeated daily administration of doses of 1 and $5 \mathrm{~g} / 100 \mathrm{~g}$ of body weight is technically impossible because of the large volume, they were administered on a single occasion. The single administrations of dose of $1 \mathrm{~g} / 100 \mathrm{~g}$ of body weight 2-3 days after LMWCC administration the animals growth rate decreased, but later these animals not differed from control group in growth rate. did not influence on the growth rate, and a dose of $5 \mathrm{~g} / 100 \mathrm{~g}$ of body weight stimulated the increase of body weight to the greatest extent after a single administration at 3-7 days in comparison with the small doses, the animals also exceeded the control group by 16-17 g (Figure 2).
Therefore, different doses of LMWCC had a different effect on the growth rate of experimental animals: a daily dose of $0.01 \mathrm{~g} / 100$ for 7 days did not affect the body weight of the animals, repeated doses of $0.1 \mathrm{~g} /$ 100 were accompanied by an increase in the body weight of animals by 5- 7 days, a single dose of $1 \mathrm{~g} /$ 100 was accompanied by a delay in body weight growth for 2-3 days, and later these animals did not differ from control ones, a single dose of $5 \mathrm{~g} / 100$ was accompanied by stimulation of the growth of animals.

Consequently, LMWCC did not inhibit or stimulate body weight growth during 7 days of the observations, and there was no direct dependence between the dose and effect.

However, the body weight in the control group of animals increased by $33 \%$ from the initial group at 30 days after the LMWCC administration, and it increased by $53 \%$ from the initial mass at 60 days after the LMWCC administration (Table 1).

The body weight of the animals that received the small dose $(0.01 \mathrm{~g} / 100 \mathrm{~g}$ of weight) of LMWCC did not differ from the control animals at 30 and 60 days, and those who received a dose of $0.1 \mathrm{~g} / 100 \mathrm{~g}$ of weight exceeded the control ones at 30 days but later their body weight did not change (Table 1).

At the same time, at a dose of LMWCC $1 \mathrm{~g} / 100 \mathrm{~g}$ of weight the animals were behind the the control group on body mass on $18 \%$, and they did not differ with 
Table 1: Body weight of the experimental animals as percentage of the initial at 30 and 60 days after the administration of different doses of low-molecular components of the colostrums per os

\begin{tabular}{|c|c|c|c|c|c|}
\hline \multicolumn{6}{|c|}{ Body weight (in grams) } \\
\hline \multirow{2}{*}{$\begin{array}{l}\text { Terms after the administration of } \\
\text { LMWCC, days }\end{array}$} & \multicolumn{5}{|c|}{ Dose of LMWCC, $\mathrm{g} / 100 \mathrm{~g}$ of the mass } \\
\hline & Control (0) & 0.01 & 0.1 & 1 & 5 \\
\hline 30 & $133.8 \pm 6.9$ & $129.7 \pm 4.9$ & $156.9 \pm 6.9$ & $120.5 \pm 4.7$ & $135.7 \pm 3.9$ \\
\hline 60 & $153.4 \pm 10.6$ & $149.9 \pm 8.3$ & $154.3 \pm 8.0$ & $141.7 \pm 10.0$ & $180.6^{*} \pm 15.6$ \\
\hline
\end{tabular}

control group at 30 days and exceeded the control group at 60 days at a dose of $5 \mathrm{~g} / 100 \mathrm{~g}$ of the weight (Table 1).

Therefore, the aftereffect of LMWCC depended on the dose. Thus, at a dose of $0.01 \mathrm{~g} / 100 \mathrm{~g}$ after 30 and 60 days, the body weight of the animals did not differ from the control ones, at a dose of $0.1 \mathrm{~g} / 100 \mathrm{~g}$, the animals exceeded the controls after 30 days and did not differ from the controls after 60 days; at a dose of 1 $\mathrm{g} / 100 \mathrm{~g}$, the animals lagged behind the control in both 30 and 60 days, and at a dose of $5 \mathrm{~g} / 100 \mathrm{~g}$ did not differ from the control after 30 days and exceeded the control after 60 days. Consequently, the components of LMWCC did not inhibit the growth of body weight and accelerated the growth of the animals after the cut-off of the administration, which is especially expressed at the doses of 0.1 and $5 \mathrm{~g}$ per $100 \mathrm{~g}$ of body. There is no direct connection between the intensity of body weight growth and the dose of LMWCC.

\section{The Liver, Spleen and Kidney Mass Variation}

It is demonstrated that the relative weight of the liver changes during the ontogenesis [28], at the expressed food loads [29], and various pathologies [30]. The change in the mass of organs is based on their hypertrophy (due to the proliferation or polyploidization), due to the apoptotic processes.

The administration of small doses of LMWCC to the experimental animals resulted in a slight decrease (by $15 \%$ ) of the relative weight of the liver at 30 days after the last administration of LMWCC (Table 2).

An increase of the dose of LMWCC up to $0.1 \mathrm{~g}$ per $100 \mathrm{~g}$ was accompanied by a decrease of the relative mass of this organ by $27 \%$ in comparison with the control, and an increase of the dose up to $1 \mathrm{~g}$ per $100 \mathrm{~g}$ was accompanied by a decrease even by $33 \%$ at 30 days after the administration of LMWCC (Table 2).

A super-large dose of LMWCC (5 g per $100 \mathrm{~g}$ ) resulted in a less expressed decrease of the relative mass of the liver in comparison with a dose of $1 \mathrm{~g} / 100$ $g$ of weight. Such a non-linear nature of the change of the liver mass can be explained by the possible hypertrophy of the liver with such a large dose of LMWCC.

The relative weight of the liver was restored at 60 days after the last administration of LMWCC (Table 2). Thus, in the group of animals receiving a dose of 0.01 $\mathrm{g} / 100 \mathrm{~g}$ of weight, it did not differ from the control

Table 2: The change of the relative weight of the organs in percentage relative to the body weight at 30 and 60 days after the start of the first administration of low-molecular components of the colostrum

\begin{tabular}{|c|c|c|c|c|c|c|}
\hline \multirow{2}{*}{$\begin{array}{c}\text { Doses of LMWCC, } g / 100 \mathrm{~g} \text { of } \\
\text { the mass }\end{array}$} & \multicolumn{2}{|c|}{ Liver } & \multicolumn{2}{|c|}{ Spleen } & \multicolumn{2}{|c|}{ Kidneys } \\
\hline & 30 days & 60 days & 30 days & 60 days & 30 days & 60 days \\
\hline Control & $\begin{array}{c}4.92 \\
\pm 0.28\end{array}$ & $\begin{array}{c}4.92 \\
\pm 0.28\end{array}$ & $\begin{array}{c}0.72 \\
\pm 0.05\end{array}$ & $\begin{array}{c}0.72 \\
\pm 0.05\end{array}$ & $\begin{array}{c}0.82 \\
\pm 0.10\end{array}$ & $\begin{array}{c}0.82 \\
\pm 0.10\end{array}$ \\
\hline 0.01 & $\begin{array}{c}4.20 \\
\pm 0.09\end{array}$ & $\begin{array}{c}4.86 \\
\pm 0.34\end{array}$ & $\begin{array}{c}0.35^{*} \\
\pm 0.01\end{array}$ & $\begin{array}{c}0.41^{*} \\
\pm 0.01\end{array}$ & $\begin{array}{c}0.74 \\
\pm 0.02\end{array}$ & $\begin{array}{c}0.72 \\
\pm 0.03\end{array}$ \\
\hline 0.1 & $\begin{array}{l}3.61^{*} \\
\pm 0.11\end{array}$ & $\begin{array}{c}4.66 \\
\pm 0.19\end{array}$ & $\begin{array}{c}0.36^{*} \\
\pm 0.02\end{array}$ & $\begin{array}{c}0.32^{*} \\
\pm 0.03\end{array}$ & $\begin{array}{c}0.75 \\
\pm 0.04\end{array}$ & $\begin{array}{c}0.65^{*} \\
\pm 0.03\end{array}$ \\
\hline 1 & $\begin{array}{c}3.32^{*} \\
\pm 0.06\end{array}$ & $\begin{array}{c}4.51 \\
\pm 0.13\end{array}$ & $\begin{array}{c}0.45^{*} \\
\pm 0.03\end{array}$ & $\begin{array}{c}0.44^{*} \\
\pm 0.04\end{array}$ & $\begin{array}{c}0.76 \\
\pm 0.03\end{array}$ & $\begin{array}{c}0.67^{*} \\
\pm 0.03\end{array}$ \\
\hline 5 & $\begin{array}{l}3.78^{*} \\
\pm 0.11\end{array}$ & $\begin{array}{c}4.51 \\
\pm 0.23\end{array}$ & $\begin{array}{l}0.45^{*} \\
\pm 0.05\end{array}$ & $\begin{array}{l}0.41^{*} \\
\pm 0.01\end{array}$ & $\begin{array}{c}0.76 \\
\pm 0.03\end{array}$ & $\begin{array}{l}0.67^{*} \\
\pm 0.05\end{array}$ \\
\hline
\end{tabular}


group, and at a dose of $0.1 \mathrm{~g} / 100 \mathrm{~g}$ of mass it was less only by $6 \%$, at large doses of 1 and $5 \mathrm{~g} / 100 \mathrm{~g}$ of mass it was less only by $9 \%$ (Table 2 ).

Consequently, the administration of LMWCC was accompanied by a decrease of the relative weight of the liver, while there was no direct dependence between a decrease of the relative weight of the organ and the dose of LMWCC, and the relative weight of the liver was restored to the control values at 60 days after the administration.

The spleen belongs to the immunocompetent organs and the change of its relative mass may reflect the participation of the immune system in the formation of a response to the action of xenobiotics. It turned out that its weight decreased by $52 \%$ at the administration of 0.01 and $0.1 \mathrm{~g} / 100 \mathrm{~g}$ to the healthy animals, and only by $38 \%$ at doses of 1 and $5 \mathrm{~g} / 100 \mathrm{~g}$ of weight in comparison with the control at 30 days after the last administration of LMWCC (Table 2).

It had lower mass by $44 \%$ and $56 \%$ at doses of 0.01 and $0.1 \mathrm{~g} / 100 \mathrm{~g}$, respectively, in comparison with the control group of animals, and by $39 \%$ at doses of 1 and $5 \mathrm{~g} / 100 \mathrm{~g}$ of the mass at 60 days after the completion of LMWCC administration (Table 2).

Consequently, the spleen mass decreased after the administration of LMWCC and was not restored to initial values even at 60 days after the administration of LMWCC.

The relative mass of the kidneys was slightly smaller in comparison with the control animals (8-10\%) at 30 days after the administration of all the studied doses of LMWCC, and even by $20 \%$ at doses of $0.1-5$ $\mathrm{g} / 100 \mathrm{~g}$ of the mass at 60 days after the administration (Table 2).

Consequently, the repeated daily administrations of LMWCC for 7 days were accompanied by a decrease of the relative mass of the liver, spleen and kidneys. Those changes did not have the directly dependence from the dose and terms after the completion of the administration of LMWCC.

Body temperature remained unchanged after the repeated administration of LMWCC for 7 days (Table 3). Consequently, LMWCC does not possess pyrogenicity even at super-large doses.

\section{DISCUSSION}

It was shown previously that LMWCC in doses of $0.1 \mathrm{~g} / 100 \mathrm{~g}$ of a body weight have immunotropic and antioxidant properties and restore a number of physiological parameters in animals with Cu-induced liver fibrosis $[15,16]$.

In this work we showed that the administration of large and especially super-large doses of LMWCC (5 $\mathrm{g} / 100 \mathrm{~g}$ ) was accompanied by the manifestation of a complex of physiological responses. Thus, the small doses $(0.01 \mathrm{~g} / 100 \mathrm{~g})$ led to a short-term inhibition of animal activity and an increase of doses led to a prolonged persistent inhibition of activity. The inhibition of motion activity correlates with the animals' aversion to food and water intake in some cases. This behavioral pattern is also due to changes in the overall metabolism. The change in metabolism and, as a consequence, the behavior of animals was due to the induction of diarrhea. As it is known, diarrhea is a symptom complex caused by various infectious and non-infectious agents [31]. Diarrhea is a clinical manifestation of impaired absorption of water and electrolytes in the intestines and disorders of intestinal motility [32].

The danger of diarrhea lies in the fact that it can lead to dehydration of the body, malabsorption, weight loss and death in the case of acute form.

Table 3: Rectal body temperature in animals of different experimental groups from $1^{\text {st }}$ to $5^{\text {th }}$ days after a single administration of LMWCC in different doses

\begin{tabular}{|c|c|c|c|c|c|}
\hline \multicolumn{2}{|c|}{ The dynamics of body temperature changes (in ${ }^{\circ} \mathbf{C}$ ) } \\
\hline $\begin{array}{c}\text { Doses of LMWCC, } \\
\mathbf{g} / 100 \text { g of the mass }\end{array}$ & $\mathbf{1}$ & $\mathbf{2}$ & $\mathbf{3}$ & $\mathbf{4}$ & $\mathbf{5}$ \\
\hline \hline Control & $36.24 \pm 0.15$ & $36.42 \pm 0.66$ & $36.44 \pm 0.55$ & $36.57 \pm 0.47$ & $36.71 \pm 0.24$ \\
\hline 0.01 & $37.00 \pm 0.39$ & $36.7 \pm 0.42$ & $37.03 \pm 0.57$ & $37.12 \pm 0.63$ & $37.24 \pm 0.51$ \\
\hline 0.1 & $36.95 \pm 0.63$ & $37.33 \pm 0.56$ & $37.46 \pm 0.54$ & $37.59 \pm 0.55$ & $37.55 \pm 0.45$ \\
\hline 1 & $36.79 \pm 0.50$ & $36.33 \pm 0.52$ & $36.63 \pm 0.63$ & $36.74 \pm 0.15$ & $36.61 \pm 0.74$ \\
\hline 5 & $36.86 \pm 0.40$ & $36.59 \pm 0.77$ & $36.82 \pm 0.64$ & $36.48 \pm 0.32$ & $36.65 \pm 0.81$ \\
\hline
\end{tabular}


It is known that the reception of milk is accompanied by induction and increase of diarrhea in some cases [33].

The results of this work showed a complex dependence between the dose of LMWCC and the manifestation of diarrhea. Thus, in the range of doses $0.01-1 \mathrm{~g} / 100 \mathrm{~g}$, the inverse dose dependence was observed (Figure 1), and in the range of doses 1-5 $\mathrm{g} / 100$ the direct dependence was observed (Figure 1). The presence of such a complex dose dependence points at the several aspects of the LMWCC effect on the body: 1) LMWCC contains various biologically active compounds; 2 ) the threshold concentrations that cause the biological effects will change at different doses of LMWCC, and the biological response is determined by the ratio between the components that exceed the threshold concentrations (by threshold concentration we imply the concentration at which a biological response can be recorded); 3) the causes and consequences of diarrhea may be different depending on a dose. Thus, if the cause of diarrhea can be a dysbacteriosis at a small dose of $0.01 \mathrm{~g} / 100 \mathrm{~g}$ of animal weight (a rapid response of the intestinal microbiota even to small doses of LMWCC), then not only changes in the microbiota, but also the normalization of the water-electrolyte metabolism, which reduces the manifestations of diarrhea, can be present with an increase of LMWCC dose. At the same time, the intestinal motility was disrupted, along with the described symptoms, which greatly increased diarrhea that was accompanied by dehydration and death of some animals at super-large doses ( $5 \mathrm{~g} / 100 \mathrm{~g})$.

Therefore, different doses of LMWCC, can form a variety of response patterns for a multicomponent colostrum mixture, which leads to different manifestations of changes in the functions of the gastrointestinal tract.

Along with this, those animals that successfully tolerated diarrhea increased body weight actively and those animals that received a large dose of LMWCC increased it most of all. This shows the presence of components in the LMWCC that accelerate the overall metabolism.

It should be noted that these metabolic changes could persist for a long time. Thus, an increase in the body weight of animals that received large doses of LMWCC was manifested 60 days after the last injection of LMWCC.

We believe that such long-term effects in the change in body weight and mass of the spleen and partially of the kidneys even after a single administration may be due to the fact that the components of the colostrum induce long-lasting cycles. Of course, the detailed characteristics of the temporal response to biologically active compounds of natural origin require special studies, but this deserves special attention.

Reducing the mass of the liver, spleen and kidney after the administration of large doses of LMWCC can also be associated with various causes, for the elucidation of which special investigations are required. However, the data already obtained indicate significant changes in the functional characteristics of these vital organs after receiving large doses of LMWCC. These functional changes persisted long enough for more than 2 months for the spleen and kidneys after a single injection of LMWCC.

The results show that even the natural products with high biological activity can deeply reorganize metabolism and require careful examination.

The super-large dose ( $5 \mathrm{~g} / 100 \mathrm{~g}$ of weight) causes diarrhea in $75 \%$, which is accompanied by the death of $15 \%$ of animals due to dehydration and intoxication. Also, this dose caused a decrease in the mass of the liver, spleen and kidneys, which slowly (at least 2 months) were restored. LMWCC do not have chronic toxicity and can be attributed to non-toxic compounds with a possible side effect - a violation of the digestive system.

\section{REFERENCES}

[1] Hurley WL, Theil PK. Perspectives on Immunoglobulins in Colostrum and Milk. Nutrients 2011; 3: 442-474. https://doi.org/10.3390/nu3040442

[2] Besser TE, Gay CC. The Importance Of Colostrum To The Health Of The Neonatal Calf. Veterinary Clinics of North America: Food Animal Practice 1994; 10(1): 107-117. https://doi.org/10.1016/S0749-0720(15)30591-0

[3] Bozhkov Al, Nikitchenko YuV, Al-Bahadly AMM. Overeating in early postnatal ontogenesis forms metabolic memory and reduces lifespan. Biomedical Journal of Gerontology and Geriatric Research 2016; 5(3): 1000309.

[4] Stelwagen K, Carpenter E, Haugh B, Hodgkinson A, Wheeler TT. Immune components of bovine colostrum and milk. J Anim Sci 2009; 87: 3-9. https://doi.org/10.2527/jas.2008-1377

[5] Brandtzaeg $P$. The mucosal immune system and its integration with the mammary glands. J Pediatr 2010; 156: S8-S15. https://doi.org/10.1016/j.jpeds.2009.11.014

[6] Tizard I. The protective properties of milk and colostrum in non-human species. In Advances in Nutritional Research: Immunological Properties of Milk; Woodward B, Draper $\mathrm{HH}$, Eds.; Kluwer Academic/Plenum Publishers: New York, NY, USA 2001; Volume 10, pp. 139-166. 
[7] Elizondo-Salazar JA, Heinrichs AJ. Feeding heat-treated colostrum to neonatal dairy heifers: Effects on growth characteristics and blood parameters. J Dairy Sci 2009; 92: 3265-3273.

https://doi.org/10.3168/jds.2008-1667

[8] Williams DR, Pithua P, Garcia A, Champagne J, Haines DM, Aly SS. Effect Three Colostrum Diets on Passive Transfer of Immunity and Preweaning Health in Calves on a California Dairy following Colostrum Management Training. Veterinary Medicine International 2014; 1 -9.

https://doi.org/10.1155/2014/698741

[9] Xu ML, Kim HJ, Chang DY, Kim H-J. The effect of dietary intake of the acidic protein fraction of bovine colostrum on influenza A (H1N1) virus infection. Journal of Microbiology 2013; 51(3): 389-393.

https://doi.org/10.1007/s12275-013-2683-y

[10] Patıroğlu T, Kondolot $M$. The effect of bovine colostrum on viral upper respiratory tract infections in children with immunoglobulin A deficiency.The Clinical Respiratory Journal 2013; 7(1): 21-26. https://doi.org/10.1111/j.1752-699X.2011.00268.x

[11] Parreño V, Marcoppido G, Vega C, Garaicoechea L, Rodriguez D, Saif L, Ferñandez F. Milk supplemented with immune colostrum: Protection against rotavirus diarrhea and modulatory effect on the systemic and mucosal antibody responses in calves experimentally challenged with bovine rotavirus. Vet Immunol Immunopathol 2010; 136: 12-27. https://doi.org/10.1016/j.vetimm.2010.01.003

[12] Gao W, Chen L, Xu LB, Huang XH. Specific activity against diarrheagenic bacteria in bovine immune milk and effect of $\mathrm{pH}$ on its antigen-binding activity upon heating. J Dairy Res 2010; 77: 220-224.

https://doi.org/10.1017/S0022029910000014

[13] Viza D, Fudenberg HH, Palareti A, Ablashi D, De Vinci C, et al. Transfer Factor: an Overlooked Potential for the Prevention and Treatment of Infectious Diseases. Folia Biologica; Praha 59.2 2013; 53-67.

[14] Struff WG, Sprotte G. Bovine colostrum as a biologic in clinical medicine; a review-Part II: Clinical studies. Int J Clin Pharmacol Ther 2008; 46: 211-225. https://doi.org/10.5414/CPP46211

[15] Bozhkov Al, Nikitchenko YuV, Lebid KM, Ivanov EG, Kurguzova NI, Gayevoy SS, Sharko MO, Alsardia MMA, Al Begai MAY. Low Molecular Weight Components from Various Sources Eliminate Oxidative Stress and Restore Physiological Characteristic of Animals at Early Stages of Cu-Induced Liver Fibrosis Development. Translational Biomedicine 2017; 8(2): 107.

[16] Bozhkov Al, Linkevych OS, Ivanov EG, Klimova OM, AIBegai MAY. Low molecular weight components of colostrum regulate the activity of cellular component of the immune system in animals with Cu-induced liver fibrosis. International Journal of Current Research 2016; 8(12): 44129-44137.

[17] Kurguzova NI, Bozhkov Al, Nikitchenko YuV, AlBegai MAY, Goltvyansky AV, Alsardia MMA, Bozhkov AA. Interconnection of Antitoxic and Antioxidant Systems of the Organism under the Action of Natural Low Molecular Complex - Fungidol. American Journal of Biomedical and Life Sciences. Special Issue: Mechanisms of Protection against Oxidative Stress 2015; 2(6-1): 25-32.

[18] Bozhkov Al, Ivanov EG, Al Begai MAY, Alsardia MMA, Kurguzova NI. Low-Molecular Weight Cow Colostrum Components in Functional Nutrition Journal of Nutritional Therapeutics 2017; 6: 11-17.

[19] Shapovalov S, Rosso L, Bozhkov A. Changes in the composition of mammary gland secretions in the first ten days of lactation. BiologicheskiyVestnik (in Russian) 2010; 1 : 22-29.

[20] Senda A, Fukuda K, Ishii T, Urashima T. Changes in the bovine whey proteome during the early lactation period. Anim Sci J 2011; 82(5): 698-706.

https://doi.org/10.1111/j.1740-0929.2011.00886.x

[21] Hernández-Castellano LE, Argüello A, Almeida AM, Castro $\mathrm{N}$, Bendixen $\mathrm{E}$. Colostrum protein uptake in neonatal lambs examined by descriptive and quantitative liquid chromatography-tandem mass spectrometry. J Dairy Sci 2015; 98(1): 135-147.

https://doi.org/10.3168/jds.2014-8143

[22] Sánchez-González DJ, Sosa-Luna CA, Vásquez-Moctezuma I. Transfer factors in medical therapy. Med Clin (Barc) 2011; 137(6): 273-277. https://doi.org/10.1016/j.medcli.2010.05.002

[23] Gotzsche PC, Johansen HK. Meta-analysis of short term low dose prednisolone versus placebo and non-steroidal antiinflammatory drugs in rheumatoid arthritis. BMJ 1998; 316: 811-818. https://doi.org/10.1136/bmj.316.7134.811

[24] National Toxicology Program's report of the endocrine disruptors low dose peer review. National Institute of Environmental Health Sciences, NIH National Toxicology Program 2001.

[25] Rollin BE. The Regulation of Animal Research and the Emergence of Animal Ethics: A Conceptual History. Theoretical Medicine and Bioethics 2006; 27(4): 285-304. https://doi.org/10.1007/s11017-006-9007-8

[26] Ma MCJ, Pettus JM, Jakoubek JA, et al. Contribution of independent and pleiotropic genetic effects in the metabolic syndrome in a hypertensive rat. Thameem F, ed. PLoS ONE 2017; 12(8): e0182650.

[27] Choi D-H, Hur Y-I, Kang J-H, et al. Usefulness of the Waist Circumference-to-Height Ratio in Screening for Obesity and Metabolic Syndrome among Korean Children and Adolescents: Korea National Health and Nutrition Examination Survey, 2010-2014. Nutrients 2017; 9(3): 256. https://doi.org/10.3390/nu9030256

[28] Tiniakos DG, Anstee QM, Burt AD. Macsween's Pathology of the Liver 2017; 308.

[29] Buha A, Milovanović V, Antonijević B, Bulat Z, Matović V. Relative Liver Weight in Rats Subacutely Exposed to Polychlorinated Biphenyls. Environmental Security Assessment and Management of Obsolete Pesticides in Southeast Europe 19 March 2013; pp. 287-294. https://doi.org/10.1007/978-94-007-6461-3_26

[30] Marchesini G, Petta S, Dalle GR. Diet, weight loss, and liver health in nonalcoholic fatty liver disease: Pathophysiology, evidence, and practice. Hepatology 2016; 63: 2032-2043. https://doi.org/10.1002/hep.28392

[31] Pancheva-Dimitrova RZ, Georgieva-Shakola M, Tzaneva V. Probiotics and antibioticassociated diarrhea in children. Abstracts of 12 UEGW, Gut 2004; 53(SuppI VI): A137.

[32] Krause R, Krejs G, Wenisch C, Reisinger EC. Elevated fecal Candida counts in patients with antibiotic-associated diarrhea: role of soluble fecal substances. Clinical and Diagnostic Laboratory Immunology 2003; 10(1): 67-168. https://doi.org/10.1128/CDLI.10.1.167-168.2003

[33] Heine RG. Allergic gastrointestinal motility disorders in infancy and early childhood. Pediatr Allergy Immunol 2008; 19: 383-391.

https://doi.org/10.1111/j.1399-3038.2008.00785.x 